\title{
Effectiveness Analysis of Edmodo-Based Blended English Learning Mode
}

\author{
https://doi.org/10.3991/ijet.v14i18.11184 \\ Shuting Cao, Haiyuan Liu ${ }^{(\varpi)}$ \\ Cangzhou Normal University, Cangzhou 061001, China \\ liuhaiyuanweow@ 126 .com
}

\begin{abstract}
This paper attempts to overcome the defects of traditional English learning mode, including poor real-time communication ability, heavy reliance on individual self-discipline, and undesirable learning effect. Drawing on the theories of English learning motivation, the author analyzed the relationship between learning motivation and learning behavior in light of the Edmodo-based blended English learning mode, and put forward the English learning persistence rate formula, thus revealing the correlations between learning cost, objective external learning environment, learning motivation, and learning persistent rate. In addition, the English courses were made more pertinent according to the Ebbinghaus forgetting curve. The course test data were fitted and weighted, outputting intuitive curves on learning effect. The research results show that the Edmodo-based blended English learning mode has a significant learning effect, and a guiding significance for English learning and English teaching reform.
\end{abstract}

Keywords - edmodo, blended learning mode, English learning, ebbinghaus forgetting curve, learning motivation

\section{Introduction}

In China's education system of primary schools, middle schools and colleges, English education and English learning have always been the educational focus of all people. With the integration of the global economy, China's comprehensive national strength and economic strength are enhancing every day, and the social market environment has imposed higher requirements on English proficiency, which not only requires stronger abilities in English listening, speaking, reading and writing, but also in smooth conversation with foreigners and using English to communicate, negotiate, and interview, etc. However, ever since the Reform and Opening up in China until the present decades, the English learning effect has not been satisfactory, and most students end up in dumb English - they could listen and understand but they can't speak out. Ultimately, this is due to the unscientific traditional English teaching and learning mode, which adopts the English grammar translation method to teach students to learn English; however, this method is more suitable for translating English literature works, not for real-time communication in English environment, and it's contrary to the natural law of human language learning process. For Chinese students, English learning has 
consumed a great deal of time, but not achieved good results, so it's urgent to adjust the proportion of traditional English learning, as shown in Figure 1, and pay attention to the assessment of abilities of English speaking and writing [1].

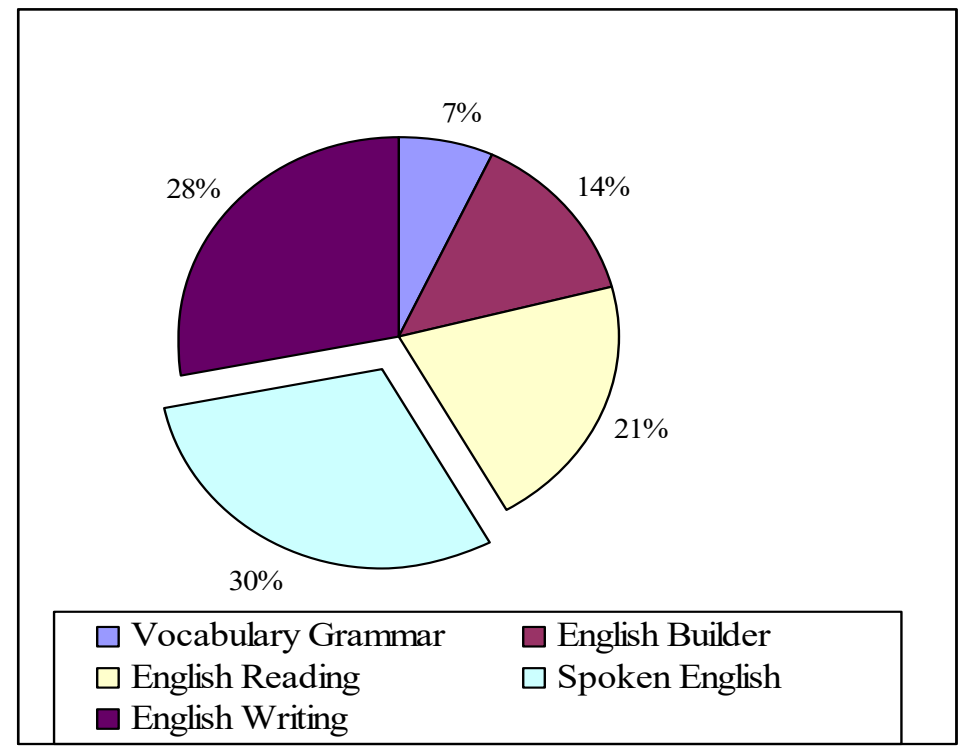

Fig. 1. English improvement requirements

In the traditional English learning mode, students and teachers conduct face-to-face passive teaching-learning activities with classrooms as the platform. The course learning focuses more on the rememberance of knowledge, grammar analysis, vocabulary and sentence structure, while ignoring the most basic nature of language learning: faceto-face impromptu communication. As a result, students' involvement and activity level in traditional classrooms are low, and long-term learning produces no corresponding ideal learning outcomes, which has discouraged the students' enthusiasm and initiative of independent learning. The market demand of English learning is huge, driven by economic interests and traditional English education, and with the continuous advancement of science and technology and the maturity and application of artificial intelligence, many online English learning tools appear on the market. But as the network environment is more complex and open, the eye-catching entertainment information would distract the students' attention, so the online English learning entirely relies on their self-control and self-discipline. Meanwhile, there is no real and effective interaction and communication between individuals, so the teachers can't supervise and manage the progress of students' learning in a timely manner, and they cannot formulate learning plans and strategies in accordance with the students' aptitude, so the students' learning efficiency is low and the learning effect is not ideal, and their learning motivation and interests could not be motivated in the long run.

According to relevant research, in various basic disciplines, there're quite a few studies on the blended learning modes, most of which are integrated with traditional 
classroom teaching to construct a blended teaching mode that combines online and offline contents as well as in-class and extracurricular activities; in 2011, under the category of "Social Network and Communication", Edmodo had been named one of the top 25 websites for innovation, creativity, active engagement and collaboration by the American Association of School Librarians [2]. The connectivism theory proposed by Siemens in 2004 and Downes in 2007 combines social learning with social media technologies. China has applied the blended learning mode to the course teaching and achieved certain results, but it did not give full play to the advantages of the blended learning mode.

The blended learning mode combines the traditional face-to-face learning with online learning [3]. Taking the advantage of the convenience of artificial intelligence and social software, with this learning mode, students could learn the course contents quickly in a timely manner, and teachers could supervise and manage the students' learning process in real time, as well as carry out comprehensive tests on English learning effect in stages; under this mode, students could master effective learning methods in a good learning environment; with the help of the Edmodo learning platform [4], the supervisory and managerial role of teachers can be fully exerted, and the productive English learning results would bring students with confidence in learning, thus their passive learning motivation could turn into positive learning motivation, and it urges them to maintain enthusiasm and interests in independent English learning.

Based on the Edmodo learning platform, this paper introduces the English learning motivation theory, and the human memory law - the Ebbinghaus forgetting curve; through tests and experiments, in terms of enhancing English learning motivation and improving learning methods and strategies, it analyzes the effectiveness of English learning under the blended learning mode.

\section{English learning effectiveness theory}

\subsection{English learning motivation theory}

English learning is a long-term and continuous process. A good and determined learning attitude, namely the learning motivation, will directly affect the English learning behaviors, so stimulating students' learning motivation is the key to the success of English learning. The predecessors have divided the learning motivation into seven types: intrinsic interest motivation, achievement motivation, personal development motivation, go-abroad motivation, social responsibility motivation, learning situational motivation and information media motivation [5]. No matter which learning motivation type, the intensity of learning motivation is determined by the internal needs and the external incentives. Subjective internal learning needs are the internal driving force, playing a leading role, the learning desire would trigger the English learning behavior and make students adopt corresponding efficient learning strategies; the objective external incentives are external stimuli that influence the English learning behavior, as shown in Figure 2 [6]. 


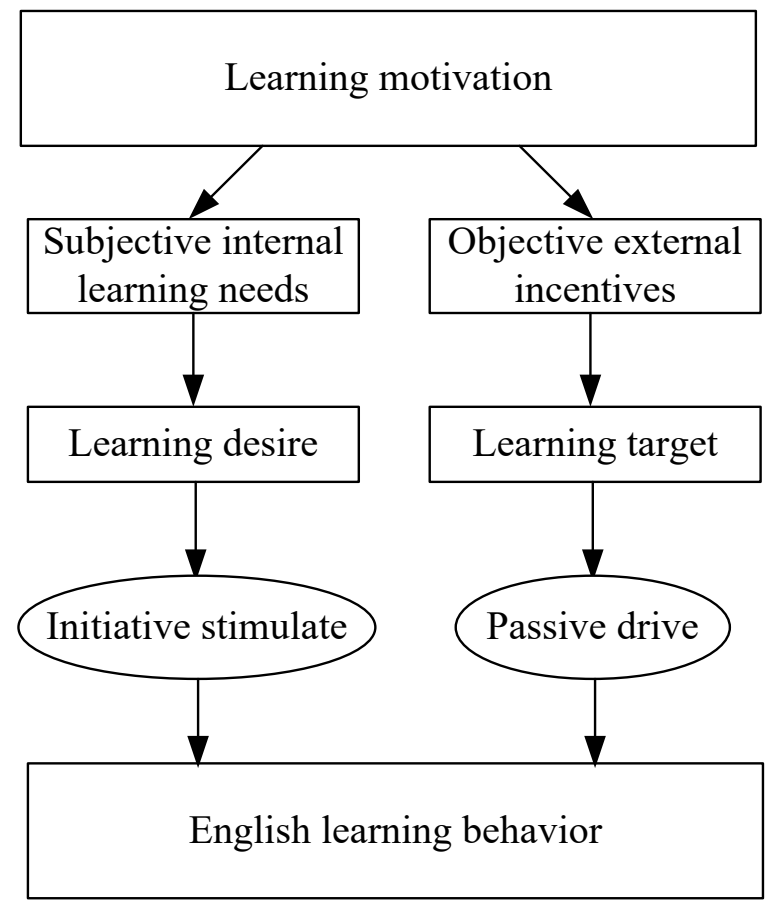

Fig. 2. Learning motivation affects learning behavior

\subsection{English learning persistence rate theory of blended learning mode}

The Edmodo-based blended learning mode has both the advantages of the traditional learning modes [7], and the advantages of online learning in flexibility and interestingness. The key for learning English under the blended learning mode is to have a strong and persistent learning motivation, and at the same time, the learning effects and results are also restricting the learning persistence rate, as shown in Formula 1.

$$
P=K \cdot M=K \cdot \frac{V}{C}
$$

where, $\mathrm{P}$ represents the learning persistence rate, $\mathrm{V}$ represents the learning effect, $\mathrm{C}$ represents the learning cost, $\mathrm{K}$ represents the objective external learning environment coefficient (negative learning environment coefficient may be smaller than 1, or even smaller than 0 , and positive learning environment coefficient is larger than 1), $\mathrm{M}$ represents the value of learning motivation. If the value of $\mathrm{M}$ is larger than 0 , it means the learner expects to be rewarded in learning effects; when the obtained learning effect is greater than the learning cost, that is, $M>1$, it helps the English learning to continue; if the obtained learning effect is less than the learning cost, that is, $0<\mathrm{M}<1$, then it's not conducive to the continuation of English learning. 
In summary, the English learning persistence rate mainly depends on the English learning motivation, and at the same time, a good learning environment could play the role of supervision and management. Realizing a good learning environment requires us to reform the English teaching contents, update teaching methods, improve teaching evaluation methods, respect the students' personalities and characteristics, use subjective learning motivation to stimulate learning strategies, promote personalized learning, and give full play to students' enthusiasm for learning.

Therefore, an effective learning mode can help students achieve good learning results, and a good learning mode can help them develop their own English learning methods and habits, as well as develop self-learning ability and enthusiasm for learning. At the same time, good learning outcomes could further trigger students' English learning motivation so that they can maintain a strong interest and enthusiasm in learning [8].

\subsection{Edmodo-based blended English learning process}

Edmodo is a free-of-charge e-learning management platform, with both computer client end and mobile phone client end, its download and installation are easy, and it combines the communication and exchange functions of social platforms and the learning function of learning platforms. The functional attributes of the Edmodo platform could prevent the interference of complex and adverse information, providing students and teachers with a healthy and safe learning and communication environment for their English learning. Its social platform combines the functions of Facebook and real-time interactive English learning process, and performs inter-group collaboration on the platform [9].

Teachers could use the Edmodo platform to publish English learning tasks, correct students' homework, assign course contents, conduct regular online tests and Q\&A, and send class notes and remind students to submit assignments on time. Students could download course-related PPTs and videos from the Edmodo platform, and combine with the course contents taught by teachers to conduct after-class self-learning, and then according to the online test questions of each stage (reading, writing, speaking, and other comprehensive questions) issued by the teacher, students could conduct self-test and obtain medals after passing the tests; if students fail to pass the course tests, they could communicate with teachers online in time, and seek improvement in their learning methods, combine with the download learning materials to conduct self-learning training again, and then take the self-test for several times until get the medal. Moreover, teachers can calculate the final scores by weighting the number of medals and scores at each stage, the detailed English learning flow of the Edmodo-based platform is shown in Figure 3 [4]. 


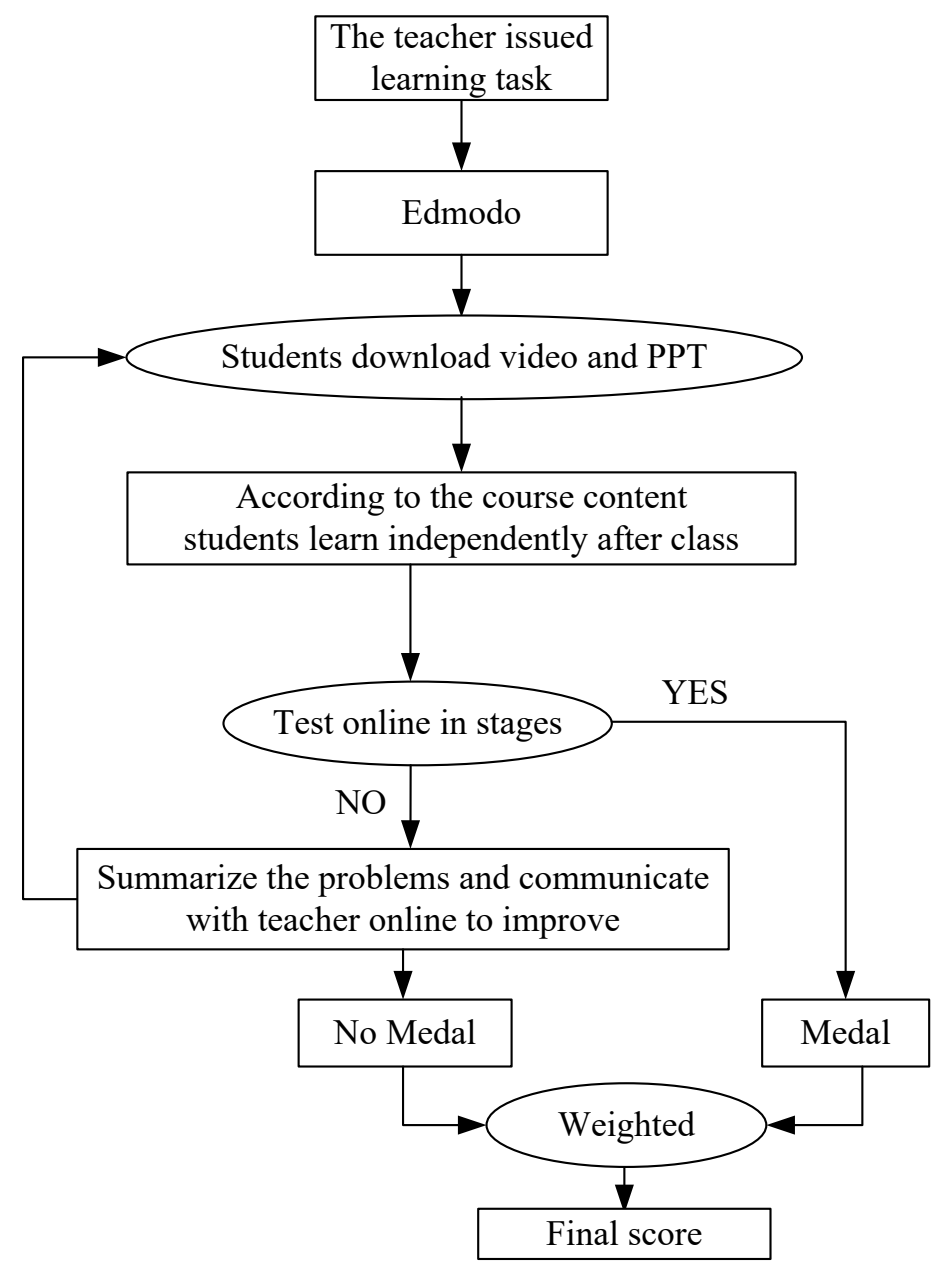

Fig. 3. English learning flow of blended learning mode based on Edmodo platform

According to the English learning flow shown in Figure 3 we can see that, in order to get the ideal test scores, students would continuously study the course materials and conduct self-tests until they get a satisfactory course score.

\section{$3 \quad$ Analysis of the Effectiveness of Blended English Learning Mode Based on Edmodo Platform}

\subsection{Course setting of blended learning mode based on Edmodo platform}

According to the Ebbinghaus Forgetting Curve (as shown in Figure 4), human memory includes short-term memory and long-term memory. The short-term memory 
cycle is roughly divided into $5 \mathrm{~min}, 30 \mathrm{~min}$, and $12 \mathrm{~h}$; and the long-term memory cycle is roughly divided into 1Day, 2Day, 4Day, 7Day, 15Day. Therefore, according to the Ebbinghaus Forgetting Curve and the law of memory cycle, we formulated a course learning plan against the forgetting rules, and published corresponding course tests in stages on the Edmodo platform [10-24].

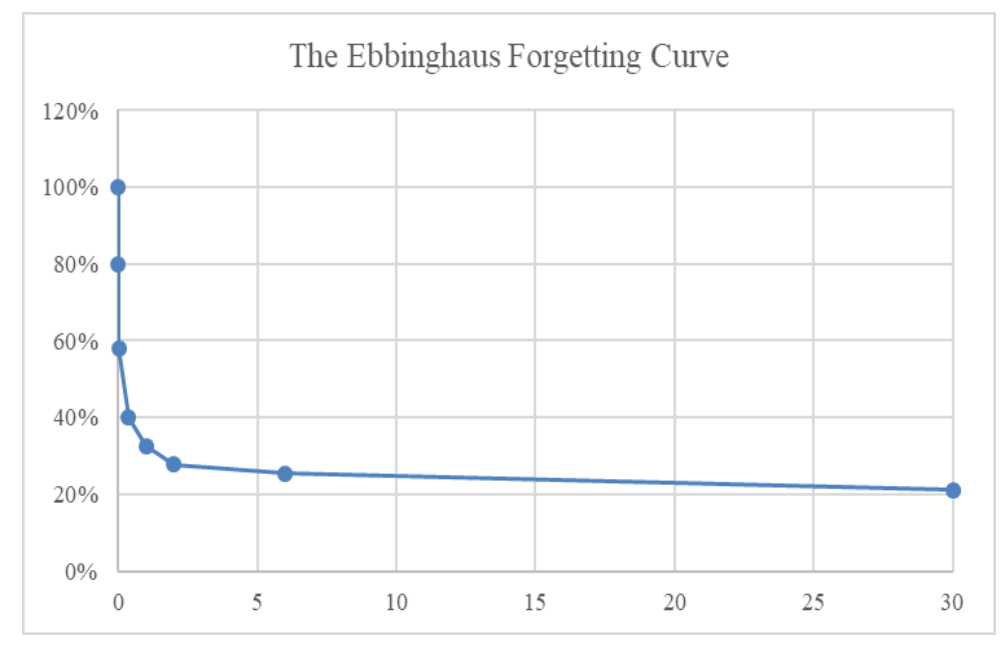

Fig. 4. The Ebbinghaus forgetting curve

Table 1. English study review schedule

\begin{tabular}{|l|l|l|}
\hline Learning days (x) & New knowledge (Tx) & \multicolumn{1}{c|}{ Collection of review knowledge (MReview) } \\
\hline $1 \leq x \leq 15$ & $\mathrm{Tx}$ & MReview $=\{\mathrm{Tx}, \mathrm{Tx}-1, \mathrm{Tx}-3, \mathrm{Tx}-7, \mathrm{Tx}-14\}$ \\
\hline $16 \leq \mathrm{x} \leq 29$ & $\mathrm{Tx}=0$ & MReview $=\{\mathrm{Tx}, \mathrm{Tx}-1, \mathrm{Tx}-3, \mathrm{Tx}-7, \mathrm{Tx}-14\}$ \\
\hline $30 \leq \mathrm{x} \leq 44$ & $\mathrm{Tx}=0$ & MReview $=\{\mathrm{Tx}-29\}$ \\
\hline
\end{tabular}

As shown in Table 1, a course plan of blended learning mode based on the Edmodo platform was formulated, where $\mathrm{x}$ represents the total learning days, 44 days; Tx represents new knowledge learnt on the day, and MReview represents the contents that need to be reviewed on the day. The new knowledge learning plan was set to be 15 days. In the first 15 days, the subjects both learnt new knowledge Tx and reviewed the learnt knowledge set MReview. After the 16th day, no new knowledge was learnt and only the old knowledge was reviewed (that is, when $\mathrm{x} \in[16,44], \mathrm{Tx}=0$ ); from the 30 th day until the 44th day, the learning content learnt in the first 15 days was reviewed.

Each semester lasts 4 months and there're 16 weeks class hours in all, the course plan stipulates to learn new knowledge in the first 15 days ( 3 weeks), from the 16th day to the 45th day, students reviewed the course according to the formula shown in Table 1. After each course, homework and tests were published on the Edmodo platform, and the published homework question bank was assigned to the students randomly, for different students, their homework assignments were different, as thus avoiding plagiarism between students. Taking this as external environment stimulus, the proposed method could urge the students to complete their homework independently, after the 
homework test is completed, the scores are calculated automatically. Within the same day, the homework test could be taken for multiple times, and the best scores will be recorded in the database, then by the end of the semester, the scores are weighted to give the final scores. The course plan for each semester was divided into 3 groups, within 16 weeks, the 3 groups of learning tasks and tests were completed, and the schedule of the courses is shown in Table 2.

Table 2. Course schedule of the 3 groups

\begin{tabular}{|c|c|c|c|}
\hline Time & Group1 & Group2 & Group3 \\
\hline 3th week & $\in[1,15]$ & +15 day & +15 day \\
\hline 6th week & $\in[16,30]$ & $\in[1,15]$ & +15 day \\
\hline 9th week & $\in[31,45]$ & $\in[16,30]$ & $\in[1,15]$ \\
\hline 12th week & & $\in[31,45]$ & $\in[16,30]$ \\
\hline 15th week & & & $\in[31,45]$ \\
\hline
\end{tabular}

\subsection{Validation of effectiveness of the blended learning mode}

A targeted English learning plan was formulated according to the forgetting law, so that the learnt content could be memorized for a longer time and the desired memory effect could be achieved. By calculating the test scores and homework results (average scores of all students) of students at all stages on the Edmodo platform, the English learning curve could be obtained as shown in Figure 5, after the curve was subject to binomial fitting, the fitting formula of the curve is obtained as: $y=0.0001 x 2+0.0037 x+0.5191$, and the English learning scores could be directly read from the figure, and the Edmodo-based blended learning mode has a significant effect on English learning which requires many memorizing tasks.

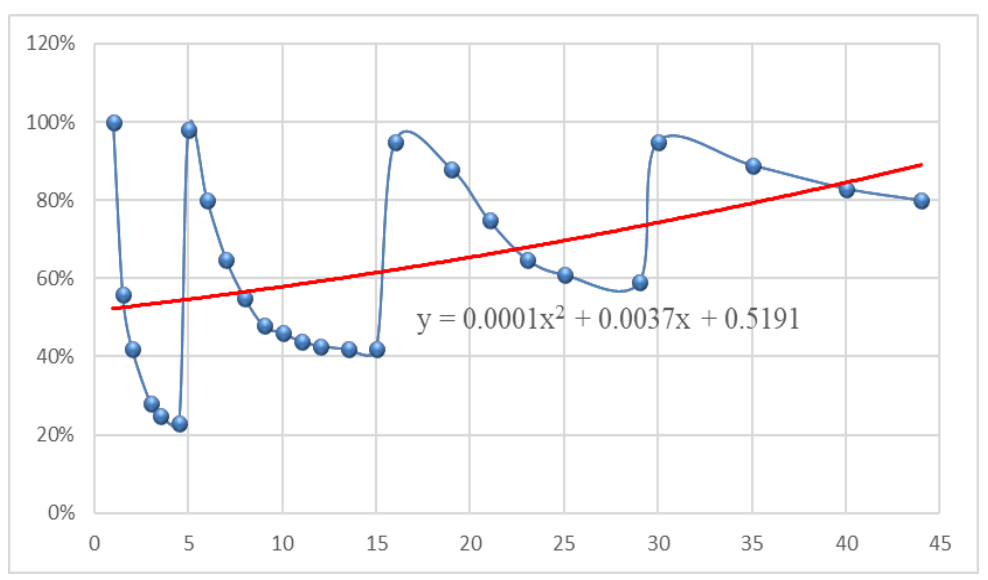

Fig. 5. The improvement curve of English learning effect 
In the blended English learning process based on Edmodo platform, the supervision, evaluation and correction functions of teachers are strengthened, and meanwhile the exchange and mutual help between individual learners are strengthened, which helps to enhance learning interests and learning motivations of the students. Figure 5 shows the improvement curve of English learning effect; it can be clearly seen that the course plan formulated under the rule of the Ebbinghaus Forbidden Curve is stable and significantly improved. The English learning environment of the Edmodo-based blended learning mode has significant learning effects in stimulating learning initiative, strengthening learning interests and maintaining persistent learning motivation, and the study in this paper has certain guiding significance for English learning and English teaching reform.

\section{Conclusion}

Based on the Edmodo learning platform, this paper introduced the English learning motivation theory, and the human memory law - the Ebbinghaus Forgetting Curve; through tests and experiments, in terms of enhancing English learning motivation and improving learning methods and strategies, it analyzed the effectiveness of English learning under the blended learning mode. The specific conclusions are as follows.

- Combining with the theory of learning motivation, this paper concluded the main internal and external factors that influence learning motivation, and discussed the interactive relationship between English learning motivation and learning behavior;

- The English learning persistence rate formula proposed in this paper revealed that the learning persistence rate is directly proportional to the learning effect, objective external learning environment and learning motivation, and it is inversely proportional to the learning cost, which has provided a clear theoretical basis for stimulating English learning initiative;

- According to the Ebbinghaus Forgetting Curve, a course learning plan against the forgetting rule had been formulated, and tests had been performed through the Edmodo platform, then the data was weighted and calculated, and the improvement curve of English learning effect was obtained.

\section{Acknowledgement}

- Study on the Training Ways of Foreign Trade English Talents in Cangzhou Local University under the background of B \& R, Cangzhou Social Science Development Research Project (NO.2018005).

- Research on Parallel Corpus Construction of English and Chinese in Cangzhou Local Agriculture under the background of Agricultural Informatization, Self-funded Project of Cangzhou Science and Technology Bureau (NO.183000020).

- Research on Talent Cultivation Path of Cangzhou Local Universities under Xi Jinping Thought on Socialism with Chinese Characteristics for a New Era, "Xi Jinping thought on Socialism with Chinese Characteristics for a New Era" Research project of Cangzhou Normal University (NO.2018015). 
- Research on O2O Online and Offline Teaching Mode of College English Courses, Cangzhou Normal University Teaching Research and Reform project in 2019

- Related Study on Students' Academic Self-Efficacy and Campus Moral Construction of Local University in Cangzhou ---a Case Study of Cangzhou Normal University, Cangzhou Social Science Development Research project (NO.2018021)

\section{References}

[1] Tang, X., Pan, Q. (2009). Study on the Application of Blended Learning in the College English Course. International Seminar on Future Information Technology \& Management Engineering. IEEE. https://doi.org/10.1109/fitme.2008.65

[2] Al-Kathiri, F. (2014). Beyond the classroom walls: edmodo in saudi secondary school efl instruction, attitudes and challenges. English Language Teaching, 8(1): 189-204. https://doi.org/10.5539/elt.v8n1p189

[3] Saovapa, W. (2014). Factors related to students' performance of hybrid learning in an English language course. International Journal of Distance Education Technologies, 12(1): 7490. http://dx.doi. org/ $10.4018 /$ ijdet.2014010105

[4] Sanders, K. S. (2012). An examination of the academic networking site edmodo on student engagement and responsible learning. Dissertations \& Theses - Gradworks.

[5] Gao, Y.H., Zhao, Y., Cheng, Y., Zhou, Y. (2012). Relationship between English learning motivation types and self-identity changes among chinese students. Tesol Quarterly, 41(1): 133-155. https://doi.org/10.1002/j.1545-7249.2007.tb00043.x

[6] Sugita, M., Takeuchi, O. (2010). What can teachers do to motivate their students? a classroom research on motivational strategy use in the japanese efl context. Innovation in Language Learning and Teaching, 4(1): 21-35. https://doi.org/10.1080/17501220802450470

[7] Alsaid, K. M. (2015). Students' perceptions of edmodo and mobile learning and their real barriers towards them. Turkish Online Journal of Educational Technology, 14(2): 167-180.

[8] Zhang, Q. M., Kim, T. Y. (2013). Cross-grade analysis of chinese students' english learning motivation: a mixed-methods study. Asia Pacific Education Review, 14(4): 615-627. https://doi.org/10.1007/s12564-013-9288-3

[9] Strambi, A., Bouvet, E. (2003). Flexibility and interaction at a distance: a mixed-mode environment for language learning. Language Learning \& Technology, 7(3): 81-102. http://dx.doi. org/10.1111/1467-9922.00234

[10] Zeng, L., Lin, L. (2011). An Interactive Vocabulary Learning System Based on Word Frequency Lists and Ebbinghaus' Curve of Forgetting. Workshop on Digital Media \& Digital Content Management. IEEE. https://doi.org/10.1109/dmdcm.2011.71

[11] Takao, S., Clifford, C.W.G., Watanabe, K. (2019). Ebbinghaus illusion depends more on the retinal than perceived size of surrounding stimuli, Vision Research, 154, 80-84. https://doi.org/10.1016/j.visres.2018.10.010

[12] Mannarino, M.R., Sahebkar, A., Bianconi, V., Banach, M., Pirro, M. (2018). PCSK9 and neurocognitive function: Should it be still an issue after FOURIER and EBBINGHAUS results? Journal of Clinical Lipidology, 12(5), 1123-1132. https://doi.org/10.1 016/j.jacl.2018. 05.012

[13] Lavrenteva, S., Murakami, I. (2018). The Ebbinghaus illusion in contrast-defined and orientation-defined stimuli, Vision Research, 148, 26-36. https://doi.org/10.1016/j.visres.20 $\underline{18.04 .006}$ 
[14] Saneyoshi, A. (2018). The Ebbinghaus illusion with small inducers appears larger on the right side, Experimental Brain Research, 236(4), 933-944. https://doi.org/10.1 007/s00221018-5168-8

[15] Todorović, D., Jovanović, L. (2018). Is the Ebbinghaus illusion a size contrast illusion? Acta Psychologica, 185, 180-187. https://doi.org/10.1016/j.actpsy.2018.02.011

[16] Chun, B.A., Heo, H.J. (2018). The effect of flipped learning on academic performance as an innovative method for overcoming ebbinghaus' forgetting curve, ACM International Conference Proceeding Series, 56-60. https://doi.org/10.1145/3178158.3178206

[17] Knol, H., Huys, R., Sarrazin, J.-C., Spiegler, A., Jirsa, V.K. (2017). Ebbinghaus figures that deceive the eye do not necessarily deceive the hand, Scientific Reports, 7(1), 3111. https://doi.org/10.1038/s41598-017-02925-4

[18] Fuss, T., Schluessel, V. (2017). The Ebbinghaus illusion in the gray bamboo shark (Chiloscyllium griseum) in comparison to the teleost damselfish (Chromis chromis), Zoology, 123, 16-29. https://doi.org/10.1016/j.zool.2017.05.006

[19] Byosiere, S.-E., Feng, L.C., Woodhead, J.K., Howell, T.J., Bennett, P.C. (2017). Visual perception in domestic dogs: susceptibility to the Ebbinghaus-Titchener and Delboeuf illusions, Animal Cognition, 20(3), 435-448. https://doi.org/10.1007/s10071-016-1067-1

[20] Giugliano, R.P., Mach, F., Zavitz, K., Wasserman, S.M., Ott, B.R. (2017). Design and rationale of the EBBINGHAUS trial: A phase 3, double-blind, placebo-controlled, multicenter study to assess the effect of evolocumab on cognitive function in patients with clinically evident cardiovascular disease and receiving statin background lipid-lowering therapy-A cognitive study of patients enrolled in the FOURIER trial, Clinical Cardiology, 40(2), 5965. https://doi.org/10.1002/clc. 22678

[21] Manning, C., Morgan, M.J., Allen, C.T.W., Pellicano, E. (2017). Susceptibility to Ebbinghaus and Müller-Lyer illusions in autistic children: a comparison of three different methods, Molecular autism, 8, 16

[22] Diener, H.C. (2017). Hypercholesterolemia. Evolocumab and cognitive functions: The EBBINGHAUS study | [Evolocumab und kognitive Funktionen: die EBBINGHAUSStudie], Arzneimitteltherapie, 35(12), 497-498

[23] Hsiao, T.C., Cheung, A., Jiang, G., Yu, X. (2016). An interactive IELTS vocabulary memorizing method based on Ebbinghaus curve, 2016 International Conference on Applied System Innovation, IEEE ICASI 2016, 7539762. 2. https://doi.org/10.1109/icasi.2016. $\underline{7539762}$

[24] Zheng, W. (2016). Design of mobile micro-English vocabulary system based on the Ebbinghaus forgetting theory, Proceedings - 8th International Conference on Internet Computing for Science and Engineering, ICICSE 2015, 7422488, 241-246. https://doi.org/10. $\underline{1109 / \text { icicse.2015.51 }}$

\section{$7 \quad$ Authors}

Shuting Cao, female, was born on October 10,1988, with a Master's degree, major in English Translation. She is currently working in Cangzhou Normal University, which is located in Hebei Province, China. She has been teaching English courses for 4 years, including College English course and CAT. She has published several papers on English teaching and translation, led 4 projects of municipal level and attended 2 projects issued by Hebei Education Department. 
Haiyuan Liu, female, was born on November 11, 1985, with a Master's degree, major in Foreign Linguistics and Applied Linguistics. She is currently working as an English teacher at Cangzhou Normal Universitry in Cangzhou, China. She has been teaching English courses for 8 years, including College English course and English for International Business. She has published several papers on English teaching. In 2017, she is excellent in annual assessment.

Article submitted 2019-07-03. Resubmitted 2019-08-11. Final acceptance 2019-08-17. Final version published as submitted by the authors. 